\title{
C-reactive protein levels, airflow obstruction, and chronic kidney disease
}

\author{
Yayoi Funakoshi $\cdot$ Hisamitsu Omori $\cdot$ \\ Shuichi Mihara · Ayumi Onoue - Yasuhiro Ogata • \\ Hisamichi Aizawa $\cdot$ Takahiko Katoh
}

Received: 3 January 2011 / Accepted: 27 March 2011/Published online: 21 April 2011

(C) The Japanese Society for Hygiene 2011

\begin{abstract}
Objectives There is some evidence that chronic obstructive pulmonary disease and chronic kidney disease (CKD) may be related, perhaps through systemic inflammation, which is common to both. However, this relationship has not yet been clearly demonstrated. The aim of this study was to investigate the association between airflow obstruction, CKD, and C-reactive protein (CRP) levels in Japanese men.

Methods The study included 11,587 men, aged 40-88 years, who underwent a health check-up. Airflow obstruction was defined as a forced expiratory volume in $1 \mathrm{~s} /$ forced vital capacity of $<70 \%$, and its severity was based on the Global Initiative for Chronic Obstructive Lung Disease guidelines (GOLD). CKD was defined as an estimated glomerular filtration rate of $<60 \mathrm{~mL} / \mathrm{min} / 1.73 \mathrm{~m}^{2}$.

Results Airflow obstruction was present in $7.9 \%$ of the participants, and $10.6 \%$ of the participants had CKD. The average CRP levels were $0.11 \pm 0.36,0.13 \pm 0.41$, and $0.18 \pm 0.41 \mathrm{mg} / \mathrm{L}$ for subjects with normal lung function, GOLD stage I, and GOLD stage II-IV, respectively. With regard to $\mathrm{CKD}$, the average CRP levels were $0.11 \pm 0.32$
\end{abstract}

Y. Funakoshi · H. Omori $(\bowtie) \cdot$ A. Onoue · T. Katoh Department of Public Health, Faculty of Life Sciences, Kumamoto University, 1-1-1 Honjou,

Kumamoto 860-8556, Japan

e-mail: omorih@gpo.kumamoto-u.ac.jp

S. Mihara · Y. Ogata

Japanese Red Cross Kumamoto Health Care Center,

Kumamoto, Japan

H. Aizawa

Division of Respirology, Neurology and Rheumatology,

Department of Medicine, Kurume University

School of Medicine, Kurume, Japan and $0.18 \pm 0.6 \mathrm{mg} / \mathrm{L}$ for subjects without and with CKD, respectively. Analysis of covariance showed no significant differences between the CRP level and lung function status or CKD after age was adjusted for. Logistic regression analysis showed no association among subjects with the three different lung function statuses after age, body mass index, hypertension, diabetes, hyper-low-density-lipoprotein-cholesterolemia, smoking, physical activity, and alcohol intake were controlled for.

Conclusions Based on the results of this study, we conclude that there is no interrelationship between CRP level, airflow obstruction, and CKD.

Keywords Chronic obstructive pulmonary disease . Chronic kidney disease - Glomerular filtration rate . C-reactive protein $\cdot$ Spirometry

\section{Introduction}

Chronic obstructive pulmonary disease (COPD) is an important public health problem [1] and a major cause of morbidity and mortality throughout the world [2]. It is predicted to become the third leading cause of death worldwide by 2020 [3]. In Japan, the Nippon COPD epidemiological (NICE) study in 2004 showed that at least $8.6 \%$ of the general population aged $\geq 40$ years suffered from COPD [4], with patients older than 70 years having the highest rate of airflow obstruction (24.4\%) of all age groups [4]. The burden of COPD is expected to increase as the world's population continues to age [5]. The Global Initiative for Chronic Obstructive Lung Disease (GOLD) guidelines recommend effective COPD management and prevention strategies [2]. Therefore, it is important to attempt to identify illnesses that are frequently linked with 
COPD and assess their impact on disease progression. Increasing evidence suggests that COPD is associated with systemic inflammation, cardiovascular diseases, diabetes, and hypertension [2, 6-8], which leads to the possibility that COPD is not only a disease of the lungs but also a systemic inflammatory disorder. However, the underlying mechanisms of COPD are still poorly understood $[2,9,10]$.

Chronic kidney disease (CKD), defined as an estimated glomerular filtration rate (GFR) of $<60 \mathrm{~mL} / \mathrm{min} / 1.73 \mathrm{~m}^{2}$, has been shown to be an independent risk factor for cardiovascular disease [11] and stroke [12] in general populations in Japan. A study involving the general Japanese population found that decreased kidney function increased the risk of first symptomatic stroke events [13]. CKD is associated with a high prevalence of hypertension, diabetes, and hypercholesterolemia [14]. The prevalence of both CKD [15] and COPD [4] increases with age. Systemic inflammation may be related to the pathogenesis of both these diseases because both COPD [16] and CKD [17] patients generally have high $\mathrm{C}$-reactive protein (CRP) levels. However, to date, there have not been any studies demonstrating this relationship in the Japanese population. The results of a study in the Netherlands suggest that airflow obstruction is associated with CKD [18]; however, no previous studies have exclusively targeted a Japanese population. The aim of this cross-sectional study, therefore, was to investigate the association between airflow obstruction, CKD, and CRP levels in Japanese men.

\section{Methods}

\section{Subjects}

The study cohort comprised 11,587 men aged $54.6 \pm$ 9.1 years [mean \pm standard deviation (SD)] who had visited the Japanese Red Cross Kumamoto Health Care Center for a multiphasic health check-up between April 2008 and March 2009. They included workers and residents of a rural area of Kumamoto, Japan. In Japan, employees generally undergo annual check-ups at their workplace or at designated clinics. The health check-up programs involve interview questionnaires, body measurements, laboratory data, lung function tests, and physical examination. Data on the medical history and lifestyle information were collected by means of interview questionnaires conducted by a public health nurse. A physician evaluated all participants and collected data on patient characteristics, physical characteristics, medical history, and lifestyle. All data were prospectively recorded and entered into an electronic database. All subjects were clinically stable (no exacerbation of underlying conditions during the previous 2 months) at the time of evaluation.
Subjects with physician-diagnosed asthma or a history of asthma or asthma-like symptoms, such as episodic breathlessness, wheezing, and cough [19], were excluded from the study. Asthma, including cough-variant asthma, was considered to be present if diagnosed by a physician. Subjects were also excluded if they had physician-diagnosed bronchiectasis, tuberculosis, or malignancy. Those with an infectious disease or other diseases associated with systemic inflammation, such as rheumatoid arthritis, connective tissue disorders, or inflammatory bowel disease, were also excluded. Subjects who had undergone pneumoconiosis screening were excluded. Of the 15,163 participants initially enrolled in the study, 11,587 men aged 40 years or older underwent lifestyle and body measurement assessment, laboratory tests, and lung function tests. Our research protocol was approved by the Human Ethics Committee of Kumamoto University and the Japanese Red Cross Kumamoto Health Care Center. All subjects gave informed consent prior to receiving the multiphasic health check-up.

\section{Measurements}

After an overnight fast, blood samples were obtained to measure serum levels of routine medical check-up markers, including low-density lipoprotein cholesterol (LDL-C), fasting glucose, and CRP. CRP levels were measured using a high-sensitivity latex assay. Systolic blood pressure (SBP) and diastolic blood pressure (DBP) were measured by trained nurses using an automatic digital sphygmomanometer (HEM-904; OMRON, Kyoto, Japan) placed on the upper arm at the height of the heart with the patient in a sitting position after $5 \mathrm{~min}$ of rest. The average of two measurements was used for the present analysis. Serum creatinine concentration obtained using an enzymatic method (Detaminar L-CRE; Kyowa Medics, Tokyo, Japan). Body mass index (BMI) was calculated as the weight in kilograms divided by the square of the height in meters. A detailed smoking history was used to define individuals as 'never smokers' (those who denied past and current smoking), 'former smokers' (those who reported smoking prior to the examination but denied current smoking at examination), or 'current smokers' (those who reported smoking at least one cigarette per day). Pack-years (packs of cigarettes per day multiplied by smoking years) were used as the smoking index. Alcohol intake was classified into five categories: 'non-drinkers', ' $1-2$ days per week', '3-4 days per week', '5-6 days per week', and 'daily drinkers'. Physical activity was divided into two categories: 'regular physical activity' was defined as physical activity performed regularly at least twice per week for at least $30 \mathrm{~min}$ per session throughout the year, and 'physical inactivity' was defined as engaging in 
irregular physical activity or engaging in no form of physical activity at all.

\section{Lung function tests}

Lung function tests were conducted using an electric spirometer (DISCOM-21 FX; Chest MI, Tokyo, Japan) connected to a computer for data analysis, as described previously [20]. Maneuvers were performed according to the GOLD recommendation [1] under the supervision of a certified pulmonary technologist. Daily volume calibration checks were performed using a 3-L syringe. A leak check was also performed on each day prior to testing. Measurements were obtained with the subjects standing and wearing nose clips. The maneuvers were repeated until acceptable spirograms were obtained. The obtained flowvolume and volume-time curves were analyzed visually. The best curve-the one with the largest sum of forced expiratory volume in $1 \mathrm{~s}\left(\mathrm{FEV}_{1}\right)$ and forced vital capacity (FVC) - was used for subsequent analysis. The acceptability criteria were as follows: the spirogram should have a good start, it should be free from artifacts, and exhalation should be satisfactory (duration of $\geq 6 \mathrm{~s}$ ) in accordance with the standardization of lung function testing criteria issued by the American Thoracic Society/European Respiratory Society Task Force [21]. Acceptable repeatability was considered to have been achieved when the difference between the largest and the next largest FVC and $\mathrm{FEV}_{1}$ was $\leq 0.150 \mathrm{~L}$. If the acceptability criteria were not met, testing was continued until these criteria were met with further analysis of additional acceptable spirograms. Both 'acceptable' and 'not acceptable' data were recorded on the computer, but only 'acceptable' data were subsequently analyzed. Reversibility testing was not performed in this study, as our institutional review boards considered it unacceptable to perform such testing without a strong suspicion of clinical disease. The spirometric criterion for diagnosis of airflow obstruction was a $\mathrm{FEV}_{1} / \mathrm{FVC}<70 \%$. $\mathrm{FEV}_{1} \%$ predicted is expressed as the percentage of the predicted value using the predictive equations published by the Japanese Pulmonary Function Standard in the Japanese Respiratory Society [22]. The severity of airflow obstruction was defined as per the GOLD guidelines [2], namely, GOLD stage $\mathrm{I}, \mathrm{FEV}_{1} / \mathrm{FVC}<70 \%$ and $\mathrm{FEV}_{1} \geq 80 \%$ predicted; GOLD stage II-IV, $\mathrm{FEV}_{1} / \mathrm{FVC}<70 \%$ and $\mathrm{FEV}_{1}$ $<80 \%$ predicted. The subjects were divided into three groups: a control group (normal lung function), GOLD stage I, and GOLD stage II-IV [20].

Chronic kidney disease

The GFR was calculated using the formula of Matsuo et al. [23]. This equation originated from the Modification of
Diet in Renal Disease (MDRD) Study group [24] designed for Japanese individuals, and it is recommended by the Japanese Society of Nephrology: estimated GFR $\left(\mathrm{mL} / \mathrm{min} / 1.73 \mathrm{~m}^{2}\right)=194 \times \mathrm{Scr}^{-1.094} \times \mathrm{Age}^{-0.287}$. CKD was defined as an estimated GFR $<60 \mathrm{~mL} / \mathrm{min} / 1.73 \mathrm{~m}^{2}$ [11].

\section{Other variables}

Hypertension was defined as a SBP of $\geq 140 \mathrm{mmHg}$ and/or a DBP of $\geq 90 \mathrm{mmHg}$, or current or previous use of antihypertensive mediation according to the Japanese Society of Hypertension guidelines [25]. Hyper LDL-cholesterolemia was defined as serum LDL cholesterol $\geq 140 \mathrm{mg} / \mathrm{dL}$ (3.6 mmol/l) or treatment with a statin, as per the 2007 Japanese Atherosclerosis Society guidelines [26]. Diabetes was defined as a fasting blood glucose of $\geq 126 \mathrm{mg} / \mathrm{dL}$ or treatment with insulin or oral hypoglycemic agents, as per the report of the Committee of Japan Diabetes Society on the classification and diagnostic criteria of diabetes mellitus [27].

\section{Statistical analysis}

Results are presented as the mean $\pm \mathrm{SD}$, and categorical variables are expressed as frequencies. Analysis of variance (ANOVA) with a post hoc Turkey's test and the Kruskal-Wallis test with post-hoc Bonferroni adjustment were used to assess the difference in characteristics by lung function status. Characteristics of the subjects according to the presence of CKD were compared using Student's $t$ and Mann-Whitney $U$ tests for continuous and categorical variables, respectively. Analysis of covariance (ANCOVA) with adjustment for age was performed to assess the influence of lung function status or CKD on the CRP levels because the CRP levels and prevalence of airflow obstruction and CKD increase with age. The relationship between airflow obstruction and CKD was analyzed using a logistic regression model adjusted for age, BMI, hypertension, diabetes, hypercholesterolemia, smoking (never smokers, former smokers, or current smoker), physical activity (physical inactivity or regular physical activity), and alcohol intake (non-drinkers, 1-2 days/week, 3-4 days/ week, 5-6 days/week, or everyday drinkers). All analyses were done using IBM SPSS Statistics vers. 18 software (SPSS, Chicago, IL).

\section{Results}

The characteristics of the subjects by age group are presented in Table 1. The prevalence of airflow obstruction was $7.9 \%$ in this study, which was similar to that reported in an earlier nation-wide epidemiological study in Japan in 
which air flow limitation was found in $8.6 \%$ of subjects over 40 years of age [4] (Table 1).

Figure 1 shows the age-specific prevalence of airflow obstruction and CKD. A linear-by-linear association test revealed a significant increase in the prevalence of airflow obstruction with increasing age $\left(\chi^{2}\right.$ for linear trend 435.149, $p<0.001)$ and CKD $\left(\chi^{2}\right.$ for linear trend 696.733, $p<0.001$ ) (Fig. 1).
Figure 2 shows the age-specific prevalence of CKD by lung function status. A linear-by-linear association test revealed a significant increase in the prevalence of decreased lung functional status in the presence of CKD ( $\chi^{2}$ for linear trend 15.799, $p<0.001$ ) (Fig. 2).

Table 2 shows the characteristics of the subjects by lung function status. Significant differences in lung function status were seen in relation to age, $\mathrm{BMI}, \mathrm{FEV}_{1} \%$ predicted,

Table 1 Characteristics of the subjects by age group

\begin{tabular}{|c|c|c|c|c|c|}
\hline \multirow[t]{2}{*}{ Characteristics } & \multirow[t]{2}{*}{ All $(n=11,587)$} & \multicolumn{4}{|l|}{ Age group (years) } \\
\hline & & $40-49(n=3,803)$ & $50-59(n=4,539)$ & $60-69(n=2,451)$ & $\geq 70(n=794)$ \\
\hline Age (years) & $54.6 \pm 9.1$ & $44.8 \pm 2.9$ & $54.7 \pm 2.9$ & $63.5 \pm 2.9$ & $74.2 \pm 3.8$ \\
\hline BMI $\left(\mathrm{kg} / \mathrm{m}^{2}\right)$ & $23.7 \pm 2.9$ & $24.0 \pm 3.1$ & $23.8 \pm 2.8$ & $23.4 \pm 2.6$ & $23.0 \pm 2.7$ \\
\hline $\mathrm{FEV}_{1} \%$ predicted & $94.2 \pm 11.2$ & $94.2 \pm 9.4$ & $94.1 \pm 10.7$ & $94.3 \pm 12.8$ & $94.8 \pm 16.2$ \\
\hline $\mathrm{FEV}_{1} / \mathrm{FVC}(\%)$ & $78.5 \pm 6.4$ & $80.4 \pm 5.4$ & $78.7 \pm 6.0$ & $76.5 \pm 6.7$ & $74.2 \pm 8.3$ \\
\hline Creatinine (mg/dL) & $0.12 \pm 0.37$ & $0.11 \pm 0.31$ & $0.11 \pm 0.33$ & $0.14 \pm 0.49$ & $0.14 \pm 0.39$ \\
\hline Estimated GFR $\left(\mathrm{mL} / \mathrm{min} / 1.73 \mathrm{~m}^{2}\right)$ & $74.3 \pm 13.0$ & $78.6 \pm 12.0$ & $74.4 \pm 12.5$ & $70.3 \pm 12.6$ & $65.6 \pm 13.6$ \\
\hline $\mathrm{CRP}(\mathrm{mg} / \mathrm{L})$ & $0.12 \pm 0.37$ & $0.11 \pm 0.31$ & $0.11 \pm 0.33$ & $0.14 \pm 0.49$ & $0.14 \pm 0.39$ \\
\hline Hyper-LDL-cholesterolemia (\%) & 32.5 & 31.4 & 33.1 & 32.6 & 33.2 \\
\hline Hypertension (\%) & 31.2 & 19.1 & 32.3 & 40.8 & 52.5 \\
\hline Diabetes $(\%)$ & 9.9 & 5.2 & 11.0 & 14.2 & 12.3 \\
\hline \multicolumn{6}{|l|}{ Medication } \\
\hline Treatment for cholesterolemia (\%) & 8.2 & 4.2 & 8.5 & 11.3 & 16.2 \\
\hline Treatment for hypertension (\%) & 19.2 & 7.5 & 19.9 & 29.0 & 41.1 \\
\hline Treatment for diabetes $(\%)$ & 5.2 & 1.9 & 5.5 & 8.2 & 9.1 \\
\hline Chronic kidney disease (\%) & 10.6 & 3.1 & 9.5 & 17.4 & 31.5 \\
\hline Airflow obstruction (\%) & 7.9 & 3.1 & 6.4 & 13.6 & 22.0 \\
\hline \multicolumn{6}{|l|}{ Lung function status (\%) } \\
\hline Normal lung function & 92.1 & 96.9 & 93.6 & 86.4 & 78.0 \\
\hline GOLD stage I & 3.9 & 1.5 & 3.0 & 7.0 & 11.1 \\
\hline GOLD stage II-IV & 4.0 & 1.6 & 3.4 & 6.6 & 10.9 \\
\hline \multicolumn{6}{|l|}{ Smoking history (\%) } \\
\hline Never smokers & 31.8 & 32.1 & 27.4 & 36.1 & 42.4 \\
\hline Former smokers & 38.0 & 27.7 & 40.5 & 46.3 & 47.1 \\
\hline Current smokers & 30.2 & 40.2 & 32.1 & 17.7 & 10.5 \\
\hline Pack-years $^{\text {a }}$ & $18.7 \pm 20.0$ & $14.4 \pm 14.6$ & $20.8 \pm 20.2$ & $21.2 \pm 24.1$ & $18.8 \pm 23.1$ \\
\hline \multicolumn{6}{|l|}{ Alcohol intake (\%) } \\
\hline Non-drinkers & 23.8 & 25.5 & 22.0 & 22.9 & 29.1 \\
\hline 1-2 days/week & 13.2 & 16.0 & 11.9 & 11.6 & 12.1 \\
\hline 3-4 days/week & 11.2 & 11.7 & 11.6 & 9.9 & 10.6 \\
\hline 5-6 days/week & 12.9 & 12.5 & 12.5 & 13.8 & 14.5 \\
\hline Everyday drinkers & 38.9 & 34.3 & 42.0 & 41.8 & 33.8 \\
\hline Regular physical activity ${ }^{\mathrm{b}}(\%)$ & 36.1 & 24.3 & 32.4 & 52.0 & 66.2 \\
\hline
\end{tabular}

Values are presented as the mean and, which appropriate, \pm standard deviation (SD)

$B M I$ Body mass index, $F E V_{1}$ forced expiratory volume in $1 \mathrm{~s}, F E V_{1} / F V C$ forced expiratory volume in 1 s/forced vital capacity, $C R P C$-reactive protein, GFR glomerular filtration rate, $L D L$ low-density lipoprotein

${ }^{\mathrm{a}}$ Pack-years $=$ (number of cigarettes smoked per day $\times$ number of years smoked) $/ 20$

b Regular physical activity was defined as exercising at least 2 times per week for at least 30 min per session throughout the year 

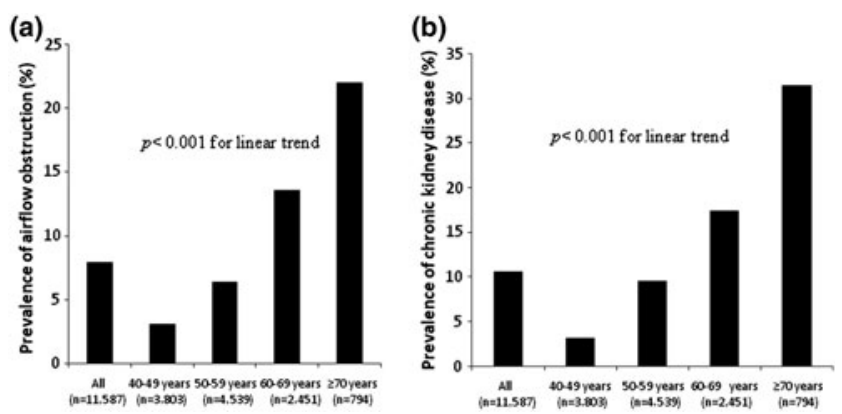

Fig. 1 Age-specific prevalence of airflow obstruction and chronic kidney disease. a Age-specific prevalence of airflow obstruction, b age-specific prevalence of chronic kidney disease (CKD). A linearby-linear association test showed a significant increase in prevalence of airflow obstruction and CKD with increasing age $(p<0.001)$

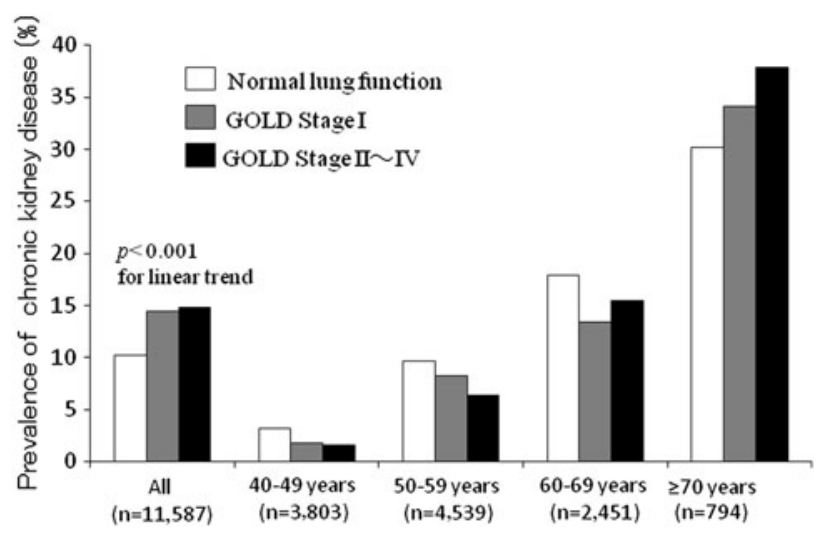

Fig. 2 Age-specific prevalence of CKD by lung function status. A linear-by-linear association test showed a significant increase in the prevalence of CKD with decreased lung function status $(p<0.001)$

$\mathrm{FEV}_{1} / \mathrm{FVC}$, estimated GFR, CRP, frequency of hypertension, frequency of treatment for cholesterolemia, hypertension, and diabetes, prevalence of CKD, pack-years and smoking history, and frequency of alcohol intake and physical activity (Table 2).

Table 3 shows the characteristics of the subjects according to the presence of CKD. Significant differences between the two groups were seen in relation to age, BMI, $\mathrm{FEV}_{1} / \mathrm{FVC}$, creatinine, estimated GFR, CRP, prevalence of hyper LDL-cholesterolemia, hypertension, and diabetes, frequency of treatment for cholesterolemia, hypertension, and diabetes, smoking history, pack-years, and frequency of alcohol intake and physical activity (Table 3).

Figure 3 shows the CRP levels according to lung function status or CKD. The average CRP levels were $0.11 \pm 0.36,0.13 \pm 0.41$, and $0.18 \pm 0.41 \mathrm{mg} / \mathrm{L}$ in subjects with normal lung function, GOLD stage I, and GOLD stage II-IV, respectively. ANCOVA after adjustment for age showed no statistically significant differences among these three subject groups because a significant interaction was found between lung function status and age $(F=$ $3.400, p=0.033$ ) (Fig. 3a).

With regard to CKD, the average CRP levels were found to be $0.11 \pm 0.32$ and $0.18 \pm 0.6 \mathrm{mg} / \mathrm{L}$ for subjects without and with CKD, respectively. Further, similar to the results for lung function status, ANCOVA after adjustment for age showed no statistically significant differences between these two groups because a significant interaction was found between CKD and age $(F=3.400, p=0.033)$ (Fig. 3b).

Table 4 shows the relationship between airflow obstruction and CKD in subjects according to the severity of the airflow obstruction. After adjustment for age, BMI, hypertension, diabetes, hyper-LDL-cholesterolemia, smoking, physical activity, and alcohol intake, the logistic regression analysis showed no association among subjects with normal lung function, airflow obstruction with GOLD stage I, or airflow obstruction with GOLD stage II-IV (Table 4).

\section{Discussion}

In this study, we found no significant association between airflow obstruction and CKD according to logistic regression analysis after adjusting for age, BMI, hypertension, diabetes, hyper-LDL-cholesterolemia, smoking, physical activity, and alcohol intake. van Gestel et al. [18] investigated that association between COPD and CKD as defined by the MDRD formula (estimated GFR $<60 \mathrm{~mL} / \mathrm{min} /$ $1.73 \mathrm{~m}^{2}$ ) in 3,358 vascular surgery patients (mean age 66 years) in The Netherlands. Although they did not observe significant association for those with mild COPD [odds radio (OR) 1.23, 95\% confidence interval $(95 \% \mathrm{CI})$ 0.99-1.53)] or those with severe COPD (OR 0.80, 95\% CI $0.54-1.20$ ), there was a slight significant relationship between COPD and CKD for those with moderate COPD (OR 1.33, 95\% CI 1.07-1.65). However, the composition of the study cohorts differs between these two studies, with the subjects in the Dutch study being vascular surgery patients - while those in our study were not - and relatively older than our subjects. Mannino et al. [5] suggested that the prevalence of COPD can be attributed partly to advancing age (with the risk nearly doubling every 10 years beyond the age of 40 years) and partly due to continued smoking, which is the most important risk factor. We found that the frequency of airflow obstruction and/or CKD was the highest in subjects in the age group $\geq 70$ years. However, we could not assess the frequencies of these disorders according to age group because our sample size was small. Clearly, further studies are needed to determine the relationship between airflow obstruction and $\mathrm{CKD}$, including the effects of aging. 
Table 2 Characteristics of the subjects by lung function status

\begin{tabular}{|c|c|c|c|c|}
\hline \multirow[t]{2}{*}{ Characteristics } & \multirow[t]{2}{*}{ Normal lung function $(n=10,669)$} & \multicolumn{2}{|l|}{ Airflow obstruction } & \multirow[t]{2}{*}{$p$} \\
\hline & & GOLD stage $\mathrm{I}(n=452)$ & GOLD stage II-IV $(n=466)$ & \\
\hline Age (years) & $54.1 \pm 8.9$ & $61.2 \pm 9.8$ & $60.8 \pm 9.6^{*}$ & $<0.001$ \\
\hline BMI $\left(\mathrm{kg} / \mathrm{m}^{2}\right)$ & $23.8 \pm 2.9$ & $22.9 \pm 2.5$ & $23.2 \pm 2.9^{*}$ & $<0.001$ \\
\hline $\mathrm{FEV}_{1} \%$ predicted & $95.6 \pm 9.6$ & $89.2 \pm 7.7$ & $66.7 \pm 11.2 *$ & $<0.001$ \\
\hline $\mathrm{FEV}_{1} / \mathrm{FVC}(\%)$ & $79.7 \pm 4.8$ & $66.2 \pm 2.9$ & $62.2 \pm 6.9^{*}$, & $<0.001$ \\
\hline Creatinine $(\mathrm{mg} / \mathrm{dL})$ & $0.88 \pm 0.31$ & $0.87 \pm 0.21$ & $0.85 \pm 0.14$ & 0.17 \\
\hline Estimated GFR $\left(\mathrm{mL} / \mathrm{min} / 1.73 \mathrm{~m}^{2}\right)$ & $74.4 \pm 12.9$ & $72.8 \pm 14.1$ & $74.0 \pm 13.9$ & $<0.05$ \\
\hline CRP (mg/L) & $0.11 \pm 0.36$ & $0.13 \pm 0.41$ & $0.18 \pm 0.41^{*}$ & $<0.05$ \\
\hline Hyper-LDL-cholesterolemia (\%) & 32.5 & 28.5 & 35.0 & 0.10 \\
\hline Hypertension (\%) & 30.7 & 32.3 & $39.9 *$, & $<0.001$ \\
\hline Diabetes $(\%)$ & 9.9 & 7.5 & $12.7^{\#}$ & 0.32 \\
\hline \multicolumn{5}{|l|}{ Medication } \\
\hline Treatment for cholesterolemia $(\%)$ & 8.0 & 8.0 & $13.1 *$ & $<0.001$ \\
\hline Treatment for hypertension $(\%)$ & 18.8 & 19.0 & $29.2 *$, & $<0.001$ \\
\hline Treatment for diabetes $(\%)$ & 5.1 & 3.8 & $7.7 *$ & $<0.05$ \\
\hline Chronic kidney disease (\%) & 10.2 & 14.4 & 14.8 & $<0.001$ \\
\hline Smoking history (\%) & & & & $<0.001$ \\
\hline Never smokers & 32.9 & 25.2 & 14.6 & \\
\hline Former smokers & 37.9 & 40.3 & 38.4 & \\
\hline Current smokers & 29.3 & $34.5^{*}$ & $47.0 *$ & \\
\hline Pack-years $^{\mathrm{a}}$ & $17.5 \pm 18.9$ & $26.0 \pm 23.9$ & $37.5 \pm 27.5^{*}$ & $<0.001$ \\
\hline Alcohol intake (\%) & & & & $<0.05$ \\
\hline Non-drinkers & 23.5 & 23.9 & 30.9 & \\
\hline 1-2 days/week & 13.6 & 8.6 & 9.4 & \\
\hline 3-4 days/week & 11.5 & 8.2 & 6.9 & \\
\hline 5-6 days/week & 12.9 & 12.6 & 12.2 & \\
\hline Everyday drinkers & 38.4 & $46.7 *$ & 40.6 & \\
\hline Regular physical activity ${ }^{\mathrm{a}}(\%)$ & 35.2 & $45.6^{*}$ & $39.5^{\#}$ & $<0.001$ \\
\hline
\end{tabular}

${ }^{*} p<0.05$ compared with normal lung function; ${ }^{*} p<0.05$ compared with GOLD stage I

Data were analyzed by analysis of variance (ANOVA) and post-hoc Tukey test or Kruskal-Wallis test and post-hoc Bonferroni adjustment. Values are presented as the mean and, where appropriate, $\pm \mathrm{SD}$

GOLD Global Initiative for Chronic Obstructive Lung Disease guidelines [2]

${ }^{a}$ Pack-years and Regular physical activity are as defined in the footnote to Table 1

Gan et al. [16] performed a systematic review and metaanalysis of 14 studies which confirmed the strong association between COPD and biological markers of systemic inflammation, such as CRP and fibrinogen levels, white blood cell count, and tumor necrosis factor alpha levels. In a cohort of 4,320 subjects (63.2\% women) selected from the Jackson Heart Study, the CRP level was higher in those with CKD than in those without it [17]. In contrast to the results of previous studies, our results show no association between the CRP levels and lung function status or CKD after age adjustment, although they do indicate that CRP levels and prevalence of airflow obstruction and CKD increased with age. A large-scale prospective study is needed to clarify the effects of aging on the relationship between CRP levels and airflow obstruction or CKD.

COPD and asthma are conditions with many comorbidities, albeit asthma to a lesser extent than COPD [2831]. To date, very limited data have been gathered on the association between asthma and CKD. Soriano et al. [29] reported an association between asthma and renal and urinary disorders in which they showed the baseline rates of comorbidities and selected medical events in COPD and asthma patients and the relative risk (RR) compared to participants without COPD or asthma, respectively [29]. The renal and urinary disorder RRs were slightly higher for COPD patients (RR 1.53, 95\% CI 1.3-1.7) than asthma 
Table 3 Characteristics of the subjects by chronic kidney disease

\begin{tabular}{|c|c|c|c|}
\hline Characteristics & $\operatorname{CKD}(-)(n=10,362)$ & $\operatorname{CKD}(+)(n=1,225)$ & $p$ \\
\hline Age (years) & $53.8 \pm 8.7$ & $61.5 \pm 9.4$ & $<0.001$ \\
\hline BMI $\left(\mathrm{kg} / \mathrm{m}^{2}\right)$ & $23.7 \pm 2.9$ & $23.9 \pm 2.6$ & $<0.05$ \\
\hline $\mathrm{FEV}_{1} \%$ predicted & $94.2 \pm 11.1$ & $94.7 \pm 12.3$ & 0.12 \\
\hline $\mathrm{FEV}_{1} / \mathrm{FVC}(\%)$ & $78.6 \pm 6.4$ & $77.3 \pm 6.6$ & $<0.001$ \\
\hline Creatinine $(\mathrm{mg} / \mathrm{dL})$ & $0.84 \pm 0.10$ & $1.19 \pm 0.80$ & $<0.001$ \\
\hline Estimated GFR $\left(\mathrm{mL} / \mathrm{min} / 1.73 \mathrm{~m}^{2}\right)$ & $76.8 \pm 11.1$ & $53.1 \pm 7.6$ & $<0.001$ \\
\hline CRP (mg/L) & $0.11 \pm 0.32$ & $0.18 \pm 0.65$ & $<0.05$ \\
\hline Hyper-LDL-cholesterolemia (\%) & 31.6 & 39.5 & $<0.001$ \\
\hline Hypertension (\%) & 29.2 & 47.4 & $<0.001$ \\
\hline Diabetes $(\%)$ & 9.7 & 11.8 & $<0.05$ \\
\hline \multicolumn{4}{|l|}{ Medication } \\
\hline Treatment for cholesterolemia ( $\%)$ & 7.4 & 15.8 & $<0.001$ \\
\hline Treatment for hypertension (\%) & 17.0 & 37.6 & $<0.001$ \\
\hline Treatment for diabetes $(\%)$ & 4.9 & 7.7 & $<0.001$ \\
\hline Lung function status & & & $<0.001$ \\
\hline Normal lung function & 92.4 & 89.1 & \\
\hline GOLD stage I & 3.7 & 5.3 & \\
\hline GOLD stage II-IV & 3.8 & 5.6 & \\
\hline Smoking history (\%) & & & $<0.001$ \\
\hline Never smokers & 31.0 & 38.7 & \\
\hline Former smokers & 36.8 & 48.3 & \\
\hline Current smokers & 32.2 & 13.0 & \\
\hline Pack-years $^{\mathrm{a}}$ & $18.8 \pm 19.8$ & $17.3 \pm 21.1$ & $<0.001$ \\
\hline Alcohol intake (\%) & & & $<0.001$ \\
\hline Non-drinkers & 22.9 & 31.4 & \\
\hline 1-2 days/week & 13.3 & 12.7 & \\
\hline 3-4 days/week & 11.3 & 10.4 & \\
\hline 5-6 days/week & 12.7 & 14.8 & \\
\hline Everyday drinkers & 39.8 & 30.7 & \\
\hline Regular physical activity ${ }^{\mathrm{a}}(\%)$ & 34.5 & 49.5 & $<0.001$ \\
\hline
\end{tabular}

Data were analyzed by Student's $t$ test and the Mann-Whitney $U$ test for continuous and categorical variables, respectively. Values are presented as the mean and, where appropriate, $\pm \mathrm{SD}$

${ }^{a}$ Pack-years and Regular physical activity are as defined in the footnote to Table 1
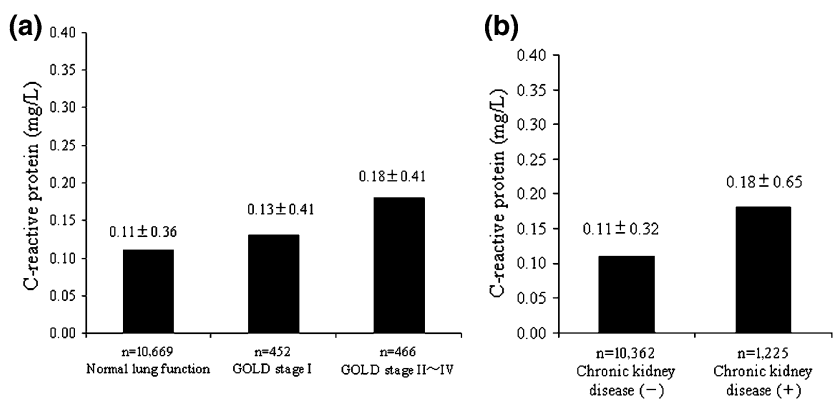

Fig. 3 C-reactive protein levels and lung function status or CKD. a C-reactive protein levels and lung function status, $\mathbf{b}$ C-reactive protein levels and CKD. Analysis of covariance after adjusting for the age showed no statistically significant differences among the three group with different lung function statuses and between the groups with and without $\mathrm{CKD}$ patients (RR 1.37, 95\% CI 1.1-1.6) [29]. The results of a more recent study indicate that asthma is weakly associated with diabetes mellitus, dyslipidemia, and cardiovascular and hypertensive disease [32]. Although asthma has been proposed to have many comorbidities [29-32], its association with CKD has not been entirely elucidated, and the underlying mechanisms remain unknown. Further research is needed to determine the interrelationships between COPD, asthma, and CKD.

Our study has a number of limitations. First, we did not employ reversibility testing, as it was unacceptable to the authors' Institutional Review Board for use in subjects without a high suspicion of disease. Although we excluded subjects with physician-diagnosed asthma from this study, the possibility that we misclassified some asthmatic 
Table 4 Relationship between airflow obstruction and chronic kidney disease according to severity of airflow obstruction

\begin{tabular}{|c|c|c|c|}
\hline \multirow[t]{2}{*}{ Logistic regression analysis } & \multirow{2}{*}{$\begin{array}{l}\text { Normal lung function } \\
(n=10,669)\end{array}$} & \multicolumn{2}{|l|}{ Airflow obstruction } \\
\hline & & GOLD stage $\mathrm{I}(n=452)$ & GOLD stage II-IV $(n=466)$ \\
\hline$n$ (\%) with chronic kidney disease & $1,091(10.2)$ & $65(14.4)$ & $69(14.8)$ \\
\hline Unadjusted OR (95\% CI) & 1.00 & $1.48(1.13-1.93)$ & $1.53(1.17-1.99)$ \\
\hline Adjusted OR (95\%) & 1.00 & $0.89(0.66-1.20)$ & $1.01(0.75-1.35)$ \\
\hline
\end{tabular}

Logistic regression analysis was adjusted for age, BMI, hypertension, diabetes, hyper-LDL-cholesterolemia, smoking, physical activity, and alcohol intake

$O R$ Odds ratio, $C I$ confidence intervals

subjects as having chronic airflow obstruction cannot be ignored, since post-bronchodilator spirometry was not performed. While asthma can usually be distinguished from COPD, it is difficult to do so in some individuals, such as those with fixed airflow obstruction [2]. The degree of reversibility of airflow obstruction is no longer recommended as a diagnostic parameter or for the differential diagnosis for COPD from asthma [2]. The modified GOLD definition, from which the reference to bronchodilation has been omitted, has been widely adopted in population-based epidemiological studies [3]. Second, we assessed only men because there were too few women with airflow obstruction. Relative to men, advanced COPD in women is characterized anatomically by smaller airway lumens and disproportionately thicker airway walls, and by emphysema that is less extensive, manifested by a smaller hole size and less peripheral involvement [33]. Further studies including Japanese women are required to determine whether there are sex differences in the association between airflow obstruction and CKD.

In conclusion, Based on the results of our study, CRP levels, airflow obstruction, and CKD are not interrelated. In our study population, the CRP levels and prevalence of airflow obstruction and CKD increased with age. A largescale prospective study is required to clarify the effects of aging on the relationships among CRP levels, airflow obstruction, and CKD.

Acknowledgments This work was supported in part by the Advanced Education Program for Integrated Clinical, Basic and Social Medicine of the Graduate School of Medical Sciences at Kumamoto University (Support Program for Improving Graduate School Education, MEXT, Japan).

Conflict of interest None declared.

\section{References}

1. Rabe KF, Hurd S, Anzueto A, Barnes PJ, Buist SA, Calverley P, Global Initiative For Chronic Obstructive Lung Disease, et al. Global strategy for the diagnosis, management, and prevention of chronic obstructive pulmonary disease: GOLD executive summary. Am J Respir Crit Care Med. 2007;176:532-55.

2. Global Initiative for Chronic Obstructive Lung Disease, April, 2001. Update 2009: Global Strategy for the diagnosis, management, and prevention of chronic obstructive pulmonary disease, NHLBI/WHO Workshop Report (in Japanese). Bethesda, National Heart, Lung and Blood Institute. Available at: http:// www.goldcopd.com. Accessed 13 Feb 2011.

3. Murray CJ, Lopez AD. Alternative projections of mortality and disability by cause 1990-2020: Global Burden of Disease Study. Lancet. 1997;349:1498-540.

4. Fukuchi $Y$, Nishimura $M$, Ichinose $M$, Adachi M, Nagai A, Kuriyama T, et al. COPD in Japan: the Nippon COPD Epidemiology study. Respirology. 2004;9:458-65.

5. Mannino DM, Buist AS. Global burden of COPD: risk factors, prevalence, and future trends. Lancet. 2007;370:765-73.

6. Rutten FH, Cramer MJ, Lammers JW, Grobbee DE, Hoes AW. Heart failure and chronic obstructive pulmonary disease: an ignored combination? Eur J Heart Fail. 2006;8:706-11.

7. Fabbri LM, Luppi F, Beghé B, Rabe KF. Complex chronic comorbidities of COPD. Eur Respir J. 2008;31:204-12.

8. Mannino DM, Thorn D, Swensen A, Holguin F. Prevalence and outcomes of diabetes, hypertension and cardiovascular disease in COPD. Eur Respir J. 2008;32:962-9.

9. Eagan TM, Ueland T, Wagner PD, Hardie JA, Mollnes TE, Damås $\mathrm{JK}$, et al. Systemic inflammatory markers in COPD: results from the Bergen COPD Cohort Study. Eur Respir J. 2010;35:540-8.

10. Spurzem JR, Rennard SI. Pathogenesis of COPD. Semin Respir Crit Care Med. 2005;26:142-53.

11. Ninomiya T, Kiyohara Y, Kubo M, Tanizaki Y, Doi Y, Okubo K, et al. Chronic kidney disease and cardiovascular disease in a general Japanese population: the Hisayama Study. Kidney Int. 2005;68:228-36.

12. Kokubo Y, Nakamura S, Okamura T, Yoshimasa Y, Makino H, Watanabe $\mathrm{M}$, et al. Relationship between blood pressure category and incidence of stroke and myocardial infarction in an urban Japanese population with and without chronic kidney disease: the Suita Study. Stroke. 2009;40:2674-9.

13. Nakayama M, Metoki H, Terawaki H, Ohkubo T, Kikuya M, Sato $\mathrm{T}$, et al. Kidney dysfunction as a risk factor for first symptomatic stroke events in a general Japanese population-the Ohasama study. Nephrol Dial Transplant. 2007;22:1910-5.

14. Nakamura K, Okamura T, Hayakawa T, Kadowaki T, Kita Y, Ohnishi H, NIPPON DATA 90 Research Group, et al. Chronic kidney disease is a risk factor for cardiovascular death in a community-based population in Japan: NIPPON DATA 90. Circ J. 2006;70:954-9.

15. Imai $\mathrm{E}$, Horio $\mathrm{M}$, Watanabe $\mathrm{T}$, Iseki $\mathrm{K}$, Yamagata $\mathrm{K}$, Hara $\mathrm{S}$, et al. Prevalence of chronic kidney disease in the Japanese general population. Clin Exp Nephrol. 2009;13:621-30. 
16. Gan WQ, Man SF, Senthilselvan A, Sin DD. Association between chronic obstructive pulmonary disease and systemic inflammation: a systematic review and meta-analysis. Thorax. 2004;59:574-80.

17. Fox ER, Benjamin EJ, Sarpong DF, Nagarajaro H, Taylor JK, Steffes MW, et al. The relation of C-reactive protein to chronic kidney disease in African Americans: the Jackson Heart Study. BMC Nephrol. 2010;11:1.

18. van Gestel YR, Chonchol M, Hoeks SE, Welten GM, Stam H, Mertens FW, et al. Association between chronic obstructive pulmonary disease and chronic kidney disease in vascular surgery patients. Nephrol Dial Transplant. 2009;24:2763-7.

19. Bateman ED, Hurd SS, Barnes PJ, Bousquet J, Drazen JM, FitzGerald M, et al. Global strategy for asthma management and prevention: GINA executive summary. Eur Respir J. 2008;31: $143-78$.

20. Funakoshi Y, Omori H, Mihara S, Marubayashi T, Katoh T. Association between airflow obstruction and the metabolic syndrome or its components in Japanese men. Intern Med. 2010;49: 2093-9.

21. Miller MR, Hankinson J, Brusasco V, Burgos F, Casaburi R, Coates A, et al. Standardisation of spirometry. Eur Respir J. 2005;26:319-38.

22. The Japanese Respiratory Society. Statement of the Japanese Pulmonary Function Standard. Revised edition 2001 (in Japanese). Available at: http://www.jrs.or.jp/quicklink/glsm/guideline/nopass_ pdf/spirogram.pdf Accessed 13 Feb 2011.

23. Matsuo S, Imai E, Horio M, Yasuda Y, Tomita K, Nitta K, et al. Collaborators developing the Japanese equation for estimated GFR. Revised equations for estimated GFR from serum creatinine in Japan. Am J Kidney Dis. 2009;53:982-92.

24. Coresh J, Astor BC, Greene T, Eknoyan G, Levey AS. Prevalence of chronic kidney disease and decreased kidney function in the adult US population: Third National Health and Nutrition Examination Survey. Am J Kidney Dis. 2003;41:1-12.

25. Ogihara T, Kikuchi K, Matsuoka H, Fujita Higaki J, Horiuchi M, Imai Y, et al. The Japanese Societey of Hypertension Guidelines for the Management of Hypertension (JSH 2009). Hypertens Res. 2009;32:3-107.

26. Japan Atherosclerosis Society. Japan Atherosclerosis Society (JAS) guidelines for prevention of atherosclerotic cardiovascular disease (in Japanese). J Atheroscler Thromb. 2007; 5-57.

27. Kuzuya T, Nakagawa S, Satoh J, Kanazawa Y, Iwamoto $Y$, Kobayashi M, et al. Report of the Committee on the classification and diagnostic criteria of diabetes mellitus. Diabetes Res Clin Pract. 2002;55:65-85.

28. Iwamoto H, Yokoyama A, Kitahara Y, Ishikawa N, Haruta Y, Yamane $\mathrm{K}$, et al. Airflow limitation in smokers is associated with subclinical atherosclerosis. Am J Respir Crit Care Med. 2009; 179:35-40.

29. Soriano JB, Visick GT, Muellerova H, Payvandi N, Hansell AL. Patterns of comorbidities in newly diagnosed COPD and asthma in primary care. Chest. 2005;128:2099-107.

30. Maqnussen $\mathrm{H}$, Watz $\mathrm{H}$. Systemic inflammation in chronic obstructive pulmonary disease and asthma: relation with comorbidities. Proc Am Thorac Soc. 2009;6:648-51.

31. Boulet LP. Influence of comorbid conditions on asthma. Eur Respir J. 2009;33:897-906.

32. Cazzola M, Calzetta L, Bettoncelli G, Novelli L, Cricelli C, Rogliani P. Asthma and comorbid medical illness. Eur Respir J. 2010. (Epub ahead of print).

33. Viegi G, Scognamiglio A, Baldacci S, Pistelli F, Carrozzi L. Epidemiology of chronic obstructive pulmonary disease (COPD). Respiration. 2001;68:4-19. 